\title{
Exploratory Research
}

National Cancer Institute

\section{Source}

National Cancer Institute. Exploratory Research. NCI Thesaurus. Code C147146.

Any action or process to perform research on a hypothetical or theoretical idea in order to determine whether the phenomena is new (which may lead to additional studies) or can be explained by an existing and well-substantiated theory. 